\title{
Linguagem e gênero na literatura agrária latina: Catão, Varrão e Virgílio
}

\author{
Matheus Trevizam \\ Universidade Estadual de Campinas
}

Brasil

Resumo. Neste trabalho faz-se uma análise comparativa do tipo de elaboração lingüística dado a dois temas relacionados à atividade agrária nas Geórgicas de Virgílio, no De agri cultura catoniano e no De re rustica de Varrão de Reate (correta localização da colméia de abelhas e enxerto arbóreo). Espera-se demonstrar que as diferenças vinculadas ao plano lingüístico no tratamento desses temas por tais autores têm relação com o fato de cada uma das obras citadas pertencer a uma tipologia genérica específica (respectivamente, poesia didática, 'tratado' e diálogo), o que significa que se observa aqui a realização diversa da linguagem em cada caso (mais ou menos objetiva, mais ou menos elaborada, mais ou menos técnica...) como conseqüência das determinações constitutivas internas a cada gênero textual.

PalaVRas-Chave. Literatura agrária latina; gêneros textuais; linguagem; Catão; Varrão; Virgílio.

É sabido que os autores da Antigüidade greco-latina, ao se disporem a compor suas obras, buscavam em geral manter-se dentro de certos limites estabelecidos pela tradição. Um dos efeitos dessa maneira de enraizar-se na prática de outros autores é justamente a constituição, ao longo do tempo, de famílias de textos relacionados entre si por nexos formais (tipos métricos, figuras de elocução, graus de elaboração da linguagem, seleção lexical...) e de outros tipos (conteudísticos, de modo de estabelecimento dos vínculos entre público e obra, de modo de construção ética dos locutores textuais...). ${ }^{1}$

Os textos dos chamados "agrônomos latinos", adotados como objeto destas considerações, permitem a observação detida dos sentidos resultantes da incorporação dos mesmos temas aproximados por estruturas genéricas

Doutorando em lingüística do IEL-UNICAMP. Bolsista FAPESP.

Email: matheustrevizam2000@yahoo.com.br.

\footnotetext{
${ }^{1}$ A respeito da idéia da constituição de 'famílias' textuais empiricamente compreendidas, cf. as idéias de K. Volk, The poetics of Latin didactic: Lucretius, Vergil, Ovid and Manilius, Oxford, University Press, 2002, p. 34 e seg.
} 
bem distintas: assim, cronologicamente, tem-se no De agri cultura catoniano algo até certo ponto afim ao modo construtivo de um tratado em prosa, na obra homônima do erudito romano Varrão de Reate um diálogo e nas Geórgicas de Virgílio o que os críticos modernos convencionaram chamar "poesia didática". É fundamental, na análise comparativa que se seguirá, atentar para as conseqüências da incorporação dos temas sobre os quais se vai focalizar a interpretação por arcabouços genéricos, como dissemos há pouco, constituídos especificamente, ou seja, através da combinação de traços que não se encontram em todos eles.

A primeira distinção que se deve fazer a esse respeito, considerando as obras mencionadas, é relativa ao fato de que apenas o texto de Virgílio a que nos referimos foi composto em forma de poesia. Evidentemente, a especificidade poética das Geórgicas representa um dado de grande importância para seu estudo, já que os antigos nos legaram numerosos testemunhos sobre a compreensão da poesia enquanto prática discursiva apartada da banalização, conforme as palavras de Cícero (Orat. 20.68):

ego autem, etiam si quorundam grandis et ornata uox est poetarum, tamen in ea cum licentiam statuo maiorem esse quam in nobis faciendorum iungendorumque uerborum, tum etiam nonnullorum uoluntati uocibus magis quam rebus inseruiunt; nec uero, si quid est unum inter eos simile - id autem est iudicium electioque uerborum -, propterea ceterarum rerum dissimilitudo intellegi non potest ...

quanto a mim, embora a dicção de certos poetas seja sublime e ornada, penso que sua liberdade ao forjar e unir palavras é maior do que a nossa; por outro lado, como ainda querem alguns, atentam mais para as palavras do que para o conteúdo. E, de fato, se há um só ponto comum entre eles - ou seja, o discernimento e escolha das palavras -, nada impede que a diferença dos demais possa ser compreendida ...

Em outras palavras, o simples fato de que Virgílio tenha escolhido desenvolver poeticamente o tema dos trabalhos rurais já nos indica que, avisados contra a ingenuidade excessiva, não devemos menosprezar na obra tudo o que nela se une ao fundo de natureza técnica para a composição de um todo coeso e fortemente intensificado em seus sentidos.

\footnotetext{
2 Sobre a classificação distinta por 'críticos' antigos ou da contemporaneidade de obras antigas atualmente consideradas 'poemas didáticos', cf. M. Trevizam, A elegia erótica romana e a tradição didascálica como matrizes compositivas da Ars amatoria de Ovídio, Dissertação de mestrado, IEL-UNICAMP, Campinas, 2003, p. 14 e seg.

${ }^{3}$ Edição utilizada: Albert Yon, Cicéron. L'Orateur. Du meilleur genre d'orateurs, Paris, Les Belles Lettres, 1964.
} 
Quanto às duas obras restantes, ou seja, ao De agri cultura de Catão Censor e ao texto varroniano, notam-se particularidades que as diferenciam não só, mais radicalmente, da elaboração extrema das Geórgicas, mas ainda entre si, no que se refere ao fato de que a secura extrema da primeira é atenuada até certo ponto por Varrão. Considerando-as sem contrapô-las ao texto de Virgílio, então, notar-se-á que a forma dialógica, reconhecidamente enriquecida por recursos ausentes de simples tratados técnicos, favorece que se eleve o grau de elaboração do texto, tornando-o, ao menos potencialmente, compatível com a expressão literária.

No tocante especificamente às diferenças verificadas no nível da realização lingüística dessas obras, parece-nos que se tem um bom parâmetro para compreendê-las em sua dimensão de textos pertencentes a gêneros distintos, o que vale dizer, relacionados a estruturas compositivas em que fatores como o modo de interação com o público são determinados pelo direcionamento de sentidos favorecido por cada família textual. Isso significa, como intentaremos demonstrar, que a forma e o grau de elaboração lingüísticos encontrados em cada um dos três textos aqui considerados corresponde, por um lado, ao que se pode esperar de obras compostas segundo os modelos seguidos pelos autores e, por outro, que essa restrição tem por finalidade permitir a própria eficácia dos processos comunicativos postos em funcionamento.

As passagens em que basearemos a análise tratam, respectivamente, do tópico da boa localização da colméia (Verg. G. 4.18-32, Varro Rust. 3.16.1217 e 3.16.27) e da técnica do enxerto arbóreo (Verg. G. 2.69-82, Varro Rust. 1.40.5-6 e 1.41.1-3 e Cato Agr. Orig. 40-42)4. Através do comentário do modo de construção do discurso nas passagens vinculadas a um mesmo item temático, buscar-se-á destacar a coerência desse nível compositivo com os demais traços integrantes do gênero dialógico, da prosa técnica em sentido estrito e da poesia didática antiga, ressaltando a necessidade de sua consideração contextualizada no interior de cada modelo genérico para a compreensão dessa coerência.

Como se sabe, Virgílio dedicou todo o quarto e último livro das Geórgicas ao desenvolvimento do tema da apicultura. Pode-se dizer, aliás, que o autor o destinou a um lugar de destaque no interior do poema, já que a nenhum dos demais tópicos tratados ao longo das quatro Geórgicas coube um livro especificamente voltado a seu tratamento. Varrão, por sua vez, inseriu o tópico da apicultura (3.16) no terceiro livro do De re rustica, em meio ao tema geral da criação comercial de pequenos animais (aves, peixes, lebres...).

\footnotetext{
${ }^{4}$ Edições utilizadas: W.D. Hooper, Cato. De agri cultura. Varro. De re rustica, London, Cambridge (Mass.), Harvard University Press, 1936 e R.F. Thomas, Virgil. Georgics, 2 v., Cambridge, University Press, 1994.
} 
Os comentadores têm destacado a importância da contribuição de Varrão como fonte de conhecimentos técnicos para Virgílio especificamente neste livro do poema, em que a repercussão de vários aspectos abordados pelo predecessor se faz sentir com alguma freqüência ${ }^{5}$. Uma observação importante a esse respeito é que a leitura comparada de trechos tematicamente afins nas Geórgicas e no De re rustica de Varrão permite restringir os limites da influência deste sobre Virgílio ao oferecimento de certos pormenores técnicos: em geral, o poeta usa de grande liberdade ao compor (inserindo novos detalhes, enfatizando outros praticamente destituídos de relevo no diálogo em questão, desenvolvendo ou eliminando pontos ali encontrados...). Portanto, a apropriação de Varrão por Virgílio não constitui uma mera tradução da prosa para a poesia, algo como a rescrita metrificada de trechos extraídos do diálogo, mas sim uma operação fortemente transformadora, em que se privilegia como objetivo a composição elaborada de um todo cujos detalhes técnicos são apenas mais um fator a contribuir para a síntese.

$\mathrm{Na}$ passagem das Geórgicas considerada aqui, tem-se, por exemplo, um eco temático direto de Varrão, encontrado nos versos de número 26 a 29, proveniente do De re rustica 3.16.27 e relacionado ao tema da necessidade da existência de "ilhotas" de pedra ou madeira em meio aos regatos, a fim de que se possibilite às abelhas molhadas por acidente secarem as asas ao sol. Ocorre, porém, que vários elementos de fundamental importância para a construção da passagem em Virgílio estão de todo ausentes em Varrão. Grosso modo, Varrão, como seria esperado para o autor de um diálogo de tema rural (afinado, portanto, com assuntos de natureza não apenas técnica, mas, pela compreensão dos antigos, mesmo filosófica), caracteriza-se pelo emprego de linguagem menos trabalhada e mais precisa do ponto-de-vista da expressão dos conhecimentos agrários ${ }^{6}$, enquanto Virgílio, sem deixar de

${ }^{5}$ Cf. comentário de R.F. Thomas às Geórgicas (1994, p. 11): 'The attitude towards Varro is comparable, though here Virgil's debt is greater; indeed, it is fair to say that the Georgics would have looked very different had Varro not published his treatise shortly before Virgil began work on his poem. Virgil used it as a source of information on a number of subjects; in the treatment of soil types, on livestock, and particularly on the bees).'

${ }^{6}$ A respeito da 'afinidade' funcional entre forma dialógica e o tratamento, especificamente, de conteúdos de ordem filosófica, cf. as observações de C. CoDOÑER ('El diálogo', in D. EsTEFANía y A. PociÑa (org.), Géneros literarios romanos: aproximación a su estudio, Madrid, Ediciones Clásicas, 1996, p. 80-81): 'Se observa, por parte de Cicerón, una tendencia a prescindir de la oratio continua como poco adecuada para la exposición de teorías filosóficas, puesto que reduce la riqueza de la misma al eliminar el contraste de pareceres. (...) La oratio perpetua se identifica com la exposición de una opinión doctrinal: sólo la inserción de interrupciones garantizaría la pluralidad de opiniones, en el debate de las quales se encuentra el procedimiento de reflexión más adecuado. De lo expuesto es lícito deducir que la presencia de personages reales a cuyo cargo corran las interrupciones no es necesaria, ya que tal función 
assemelhar-se a ele pelos assuntos, nitidamente privilegia outros aspectos da constituição significativa do texto.

Assim, fatores do tipo dos itens vocabulares empregados por cada autor para designar a colméia, bem como do oferecimento por Varrão de pormenores muito precisos, relacionados a seu posicionamento (3.16.12) e à conformação do reservatório d'água posto à disposição das abelhas (3.16.27), permitem observar com clareza a que nos referimos acima ao tratar da natureza da linguagem em um ou outro caso. Em relação ao primeiro elemento, observamos que, enquanto Varrão utiliza as expressões melittona, melitrophium, mellarium, aluarium e aluus para se referir à colônia de abelhas, Virgílio emprega as seguintes expressões nas mesmas circunstâncias: sedes, statio, aluarium, tectum, lar e cubile. Devemos observar que as expressões varronianas, como se nota pela própria presença das raízes gregas ou latinas que indicam o mel em três delas, são em geral mais técnicas, isto é, especificamente destinadas a indicar a colméia; a única exceção neste ponto dentre as expressões empregadas por ele diz respeito à palavra aluus, também passível de revestir-se de outros sentidos em latim? as designações da colméia em Virgílio caracterizam-se, quase sempre, pela maior extensão semântica: as palavras sedes, statio, tectum, lar e cubile não só se prestam a ter esta significação contextualmente direcionada mas também, é evidente, aplicam-se em outros contextos a outros sentidos. Há que se notar ainda que a falta de tecnicidade da passagem virgiliana resulta na produção de efeitos cuja eficácia não deve ser negligenciada: tratamos aqui da humanização desses insetos, obtida através do emprego de expressões que lembram diretamente a vida do homem para tratar dos animais. Elementos desse tipo, aliás, favorecem o enriquecimento de sentidos do livro quarto como um todo, já que, por seu intermédio, obtém-se a abertura para as leituras simbólicas tão comumente produzidas pelos críticos, e que tendem a buscar motivações para tais paralelos em supostas tentativas do poeta de comunicar-se de forma cifrada com seus leitores. ${ }^{8}$

puede ser desempeñada, desde el punto de vista literario, por otros elementos no definidos; así pues, la elección de personages concretos puede ser indicio de una preferencia de orden práctico: claridad en la transmisión para el lector.'

${ }^{7}$ O conhecido Novíssimo Dicionário Latino-Português de F.R.S SARAiva (Rio de Janeiro e Belo Horizonte, Livraria Garnier, 1993) oferece para o termo em questão as seguintes definições: ventre, barriga, intestinos, entranhas.

${ }^{8}$ Como típico exemplo dessa postura interpretativa, cf. a citação breve de J. Griffin por M.O LEE, Virgil as Orpheus: a study of the "Georgics", Albany, State University of New York Press, p. 92-93: 'Jasper Griffin reminds us that for Varro "bee keeping was only one branch of specialized farming... along with the raising of chickens, pigeons, peacocks, dormice, hares, deer, edible snails, and fancy fish. Virgil ignores all but the bees: for they are an image of human life"'. 
Quanto aos detalhes técnicos de indicar a direção exata da abertura da colméia (Varro Rust. 3.16.12) e a profundidade máxima do reservatório d'água (Varro Rust. 3.16.27), devemos acrescentar que nada de tão específico se encontra em Virgílio, em geral alheio a pormenorizações excessivas em razão da necessidade de fazer poesia ${ }^{9}$. A própria passagem de enumeração das espécies de plantas destinadas a servir como fonte de néctar para as abelhas e, portanto, a serem cultivadas pelo apicultor para esse fim, recebe maior cuidado em Varrão, que cita doze tipos delas (Rust. 3.16.13-14), do que em Virgílio, que se lembra de apenas quatro em três versos ( $G$. 2.3032)... Parece-nos que, em casos como esses, Varrão, compondo uma obra em que prevalece o aspecto da acuidade técnica, privilegia estender-se e detalhar mais certos pontos para adaptar-se melhor a seu intento, ou seja, a informar de modo sistemático sobre os temas; por sua vez, Virgílio não pode arriscar-se a entediar seus leitores refinados (e urbanos) através de uma abordagem realmente exaustiva dos mesmos e dosa com cautela o grau de aceitabilidade desse fator. ${ }^{10}$

Os aspectos propriamente relacionados à forma nos textos de Varrão e Virgílio também nos permitem tirar conclusões importantes para a compreensão dos objetivos dos autores ao comporem o diálogo e o poema didático em questão. Os versos de Virgílio citados acima caracterizam-se antes de mais nada pela elaboração refinada e pelo delicado equilíbrio que define o trabalho deste poeta. Observemos, de início, que o trecho temático destacado aqui foi como que ressaltado formalmente pelo autor a fim de indicar-lhe com clareza a compartimentação relativa diante do restante do livro quarto: ele flui, ao todo, por vinte e cinco versos (Virg. G. 2.18-32), ocorrendo que o que se localiza exatamente no meio (e contém a expressão in medium!) apresenta uma característica métrica que o diferencia dos demais dessa passagem, já que possui, como nenhum outro, cesura após o terceiro e o sétimo meio-pés. Os demais (anteriormente, do décimo-oitavo ao vigésimo-quarto, posteriormente, do vigésimo-sexto ao trigésimo-primeiro), apresentam todos cesura pentemímere, excetuando-se o trigésimo-segundo e derradeiro verso, que a apresenta após o sétimo meio-pé.

Além disso, Virgílio eleva a dicção através do cuidado em, de preferência, antepor os adjetivos aos termos determinados, do emprego de duas personificações mitológicas, Eurus por “vento” e Neptunus por “água” (29),

${ }^{9}$ A respeito da 'dosagem' de fatores técnicos nas Geórgicas e outros tópicos relacionados, cf. A. Dalzell, The criticism of didactic poetry: essays on Lucretius, Virgil and Ovid, Toronto, Buffalo and London, University of Toronto Press, 1996, p. 123 e seg.

${ }^{10} \mathrm{Cf}$. a respeito do modo de estabelecimento do contato entre público e obra no caso das Geórgicas a esclarecedora análise de K. VolK (2002, p. 122-139). 
do uso sugestivo de quiasmos e aliterações (18-19), do uso do tricolon ascendens (30-31) e de outros recursos caracteristicamente associáveis à escrita cultivada em latim.

Por outro lado, observamos na prosa de Varrão, autor por vezes atacado duramente em razão da irregularidade de seu estilo ${ }^{11}$, um modo expressivo que não deixa de ser claro e mais técnico do que o de Virgílio, embora de fato não se note na escrita do De re rustica o pleno alcance da harmonia elocutória. Como exemplo dos procedimentos estilísticos do autor, citemos certa tendência a apenas sobrepor elementos sintáticos, seja pela escrita freqüente de períodos simples, seja pela subordinação feita de modo que a uma oração principal se conectem várias orações subordinadas de tipo idêntico não imbricadas entre si (3.16):

Primum secundum uillam potissimum, ubi non resonent imagines (hic enim sonus harum fugae existimatur esse protelum), esse oportet aere temperato, neque aestate feruido neque hieme non aprico, ut spectet potissimum ad hibernos ortus, qui prope se loca habeat ea, ubi pabulum sit frequens et aqua pura.

Primeiro, convém que, de preferência, situe-se [a colméia] perto da casa de campo, onde o eco não ressoe, pois se julga que esse som é um sinal para voarem, em local de temperatura amena, nem escaldante no verão, nem desabrigado no inverno, que se voltem, de preferência, para o nascer do sol invernal e que haja alimento abundante e água pura por perto.

Em que pese essa limitação, no entanto, não se pode deixar de dizer que Varrão também é palatável ao leitor a seu modo, apresentando os ensinamentos agrários como falas contínuas de personagens que dialogam com outras em circunstâncias específicas e têm nomes sugestivos (Appius, neste caso, trata da apicultura) e organizando com cuidado o tratamento dos tópicos abordados através de sua divisão em subcategorias tratadas em separado.

É importante ressaltar que o relativo relaxamento de Varrão na elaboração compositiva não se estende às macro-estruturas de organização do texto, pois, como dissemos, ele procura minimizar as asperezas do tema para o público através do emprego da forma dialógica (o que permite enriquecê-lo com elementos ficcionais variados), tradicionalmente eleita por autores do

${ }^{11}$ Cf. as colocações de E. Norden, La prosa d'arte antica, edizione italiana a cura di Benedetta H. Campana, tomo I, Roma, Salerno Editrice, s/d, p. 209: 'Cosí accade, che in un uomo, il cui sguardo era volto all'indietro e che dimenticava cosí volentieri la miseria del nunc immergendosi nelle care memorie del tunc, pure poté verificarsi un'unione esteriore, dall'effetto estremamente disarmonico, fra lo stile piú moderno e artificioso e quello piú arcaico e piú semplice.' 
porte de Platão e de Cícero para a composição de obras de cunho técnico ou filosófico. Então, o autor obtém a inserção de sua obra agrária num veio compositivo prestigiado pelos antigos ao mesmo tempo em que, valendo-se dos recursos propiciados por essa mesma estrutura, informa de modo claro e convincente a respeito dos tópicos de que se ocupa, fazendo com que sejam tratados à maneira de algo diretamente comentado por especialistas. Poderse-ia mesmo dizer que a elocução simplificada que muitas vezes o caracteriza se adapta bem à mimese da fala de personagens em interação informal. ${ }^{12}$

Passando agora ao comentário dos trechos em que Catão, Varrão e Virgílio se ocupam da reprodução das plantas por enxertia, poderemos reforçar a presença de certos elementos já apontados na escrita dos dois últimos e apresentar outros caracteristicamente associáveis à prática compositiva do Censor.

Iniciando por Virgílio, nota-se que o poeta, vinculando o tratamento dessa técnica ao contexto mais amplo da reprodução vegetal ocorrida espontânea ou artificialmente (G. 2.47-72), submete a passagem como um todo a grande elaboração formal. R.F. Thomas, comentador da edição de Cambridge às Geórgicas, comprovou, por exemplo, a característica do trecho em questão enquanto cuidadosa retomada de outro anterior (2.9-34) e de mesma extensão ${ }^{13}$, ocorrida, porém, de modo a adotar com sistematicidade certas diferenças na organização dos subtópicos tratados em ambos os casos. Tal sistematicidade, diga-se de passagem, foi decerto um dos fatores que contribuiu para que o crítico citado ressaltasse a qualidade do nível compositivo do poeta justamente nos trechos técnicos da obra e não, como seria esperado, nas ditas digressões.

Os estudiosos têm observado, no tratamento da enxertia por Virgílio, que a maioria das combinações de plantas propostas por ele é fantasiosa, ou seja, impossível de ocorrer com sucesso na prática. Um crítico como D.O. Ross $^{14}$ ressaltou a estranheza de tais combinações (enxertar um ramo de macieira num plátano, por exemplo, v. 70), explicando-a como forma deliberada de tratar pejorativamente os resultados da interferência excessiva do homem no meio natural, já que, assim, produzem-se monstra capazes de causar espanto nas próprias árvores. É curioso notar que a análise do crítico traça os contornos de uma espécie de inversão entre Oriente e Ocidente pelo

\footnotetext{
${ }^{12}$ Cf. a seguinte observação de J. Gaillard e R. MARTin (Les genres littéraires à Rome, Paris, Nathan, Scodel, 1992, p. 235): 'Le tout dans un style parfois étonnant, en tout cas très éloigné des exigences de l'eloquentia et proche de ce qu'on appelait le sermo cotidianus, la "langue de tous les jours".'

${ }^{13}$ R.F. Thomas, 1994, p. 165.

${ }^{14}$ Virgil's elements: physics and poetry in the "Georgics", Princeton, New Jersey, Princeton University Press, 1987, p. 108-109.
} 
poeta, de modo que o primeiro, a que se reservou a atribuição de prodígios e de uma natureza exuberante, passa aqui a ser substituído nesse papel pela terra italiana, trabalhada em demasia por seus camponeses.

Deve-se dizer que o próprio Varrão alerta seus leitores contra a prática indiscriminada da enxertia, restringindo com cautela o alcance da técnica à união de variedades frutíferas proximamente aparentadas (Rust. 1.40.5). O fato, como já ressaltamos, de que Virgílio tenha-se servido de perto dos conhecimentos técnicos oferecidos pelo autor em várias passagens das $G e$ órgicas contribui para a compreensão dessa iniciativa do poeta como um construto ficcional, sem reais intenções de instruir os leitores: é evidente que ele conhecia o De re rustica varroniano com segurança suficiente para não se deixar enganar por negligência num ponto tão importante.

Em conformidade com uma característica largamente dispersa pelas quatro Geórgicas, nota-se que Virgílio também anima a natureza nesta passagem, através da atribuição a uma árvore do sentimento de espanto diante dos resultados da enxertia por que passou. R.F. Thomas, em comentário ao v. 2.82 da obra, cita a observação de Sérvio a respeito desse efeito, acrescentando ainda que o verbo mirari (empregado aqui na terceira pessoa do singular do perfeito, miratast) em geral se associa na dicção de Virgílio à apresentação de prodígios..$^{15}$

Além disso, a consideração do modo construtivo dos versos e dos recursos sonoros utilizados pelo poeta pode, também aqui, revelar-se esclarecedora a respeito da face da operação de escrita privilegiada na obra. Assim, os versos de número setenta e três, oitenta e oitenta e um apresentam ocorrências de interesse para uma análise mais refinada dos significados presentes na passagem. No v. 73 , em que se inicia a descrição prática de uma das técnicas de enxerto, parece-nos bastante sugestivo que se encontrem duas sinalefas e a cesura seja heptemímere: com efeito, trata-se de um trecho em que a idéia de dar continuidade e, portanto, estender uma árvore em comprimento através da junção correta do ramo de outra, está em forte evidência. Isso significa que é possível ler o retardo na introdução da pausa métrica e as sinalefas como correspondentes no plano sonoro de uma idéia contida neste verso. ${ }^{16}$

Para a compreensão do que se dá com os vv. 80-81, é preciso analisá-los conjuntamente. No v. 81, vê-se a continuidade sintática (com enjambement)

${ }^{15}$ R.F. Thomas, 1994, p. 170.

${ }^{16}$ J. Marouzeau (Traité de Stylistique latine, Paris, Les Belles Lettres, 1946), em comentário ao uso de recursos como a quantidade pelos poetas latinos, observou (p. 81): 'Il va de soi que le rythme quantitatif, soumis à des lois plus rigoureuses dans les vers que dans la prose même la mieux réglée, y prête à des effets plus expressifs.' 
do octogésimo verso. Curiosamente, todos os pés do primeiro membro do par são espondeus (exceto o quinto de um hexâmetro datílico) num verso em que se trata do crescimento dos ramos já transplantados e, portanto, de uma dilatação; além disso, o adjetivo ingens, derradeira palavra do primeiro, refere-se a nada menos do que a arbos, enfaticamente colocado como último vocábulo do segundo. Mais uma vez, portanto, o poeta encontra recursos formais para representar pelo ritmo uma noção fundamental ao tema de que se ocupa momentaneamente.

Em Catão, autor sem dúvida preocupado em orientar a prática agrícola através de seus preceitos, nada se vê nos três capítulos que dedica ao comentário da técnica de que nos ocupamos que não seja essencial à sua compreensão. Retomando um lugar-comum da crítica a respeito de seu estilo, pode-se afirmar que é caracterizado pela rudeza e pela falta de qualquer cuidado com a elaboração artística da expressão ${ }^{17}$. Basicamente, tem-se nos capítulos 40-42 do De agri cultura a construção do texto através da sucessão ininterrupta de orações independentes com verbos no imperativo.

Não se poderia fazer menção a essa monotonia de construção textual sem acrescentar que a repetição, aliás, parece constituir um elemento-chave para a prática de escrita do De agri cultura catoniano. A título de exemplificação, considere-se a retomada freqüente das mesmas estruturas sintáticas (enumerações, construções do tipo: sumito tibi / capito tibi / postea capito tibi, quod genus inserere uoles / quem inserere uoles, medullam cum medulla / medullam cum medulla...) e de certos itens vocabulares (surculum, medulla...) entre os capítulos 40 e 42.

Por outro lado, a assistematicidade da macro-organização do texto catoniano (constituído por um conjunto de rubricas que parecem seguir-se ao acaso) e o fato de que, conforme ressaltamos, tudo indica a opção neste caso por compor com propósitos práticos fazem com que se pense numa suposta influência de antecessores sobre ele essencialmente como transmissão de conteúdos técnicos. Nada se encontra aqui, portanto, parecido com os casos de Varrão e Virgílio, ambos enraizados formalmente em tradições compositivas regidas por princípios mais bem definidos.

Por fim, a monotonia lingüística do De agri cultura do autor pode ser compreendida não só como resultado de negligência formal, mas também como recurso com que ele, à sua maneira, enfatiza e procura fazer-se ex-

${ }^{17}$ Cf. por exemplo as colocações de E. Norden (La prosa... p. 177): 'Lo stile del De agri cultura è del tutto grezzo: ciò è naturale, poiché il libro deve servire all'uso pratico del contadino, e a lui egli parla nel tono che era familiare all' orecchio del rusticus dal testo delle leggi, quando nei giorni di mercato veniva in città: tutti i fenomeni che riscontriamo nel linguaggio delle leggi si ritrovano qui, e anzitutto l'assenza di ogni costruzione artistica del periodo.' 
plícito a respeito do que diz. Há que se acrescentar, aliás, que a descrição do enxerto oferecida por ele no capítulo 40 dessa obra corresponde à mais detalhada dentre aquelas escritas pelos "agrônomos" tomados como tema de nosso estudo, de maneira que provavelmente permitiria (contrastando neste ponto com a concisão virgiliana) a um interessado informar-se sobre o processo descrito e, por que não, reproduzi-lo.

Por sua vez, Varrão, que se mantém próximo de Catão ao privilegiar a função informativa ou referencial da linguagem, caracteriza-se neste trecho pelo oferecimento de conteúdos com bom grau de detalhamento, diferenciando-se dele, porém, ao compor em prosa mais fluida ${ }^{18} \mathrm{e}$, conforme explicamos, arranjar os temas com mais critério. A observação do modo de escritura da passagem varroniana revela que o autor, de fato, sem desenvolver-se muito neste ponto, subordina mais do que Catão e utiliza conectivos que relacionam períodos distintos entre si (caso de expressões como itaque, a quo fit ut, contra...), o que contribui para que as transições não se dêem de forma tão abrupta em seu texto. No que diz respeito à disposição dos tópicos e subtópicos, esse autor ramifica a informação, o que vale dizer, parte do geral para o particular derivando daquele os pontos a serem abordados em seguida com maiores detalhes; esse é o caso da técnica da enxertia, que se insere no tópico geral dos vários modos de reprodução das plantas enumerados e discutidos brevemente no trecho 40.1-5 do De re rustica e é desenvolvida na passagem que comentamos aqui.

Assim, esperamos ter demonstrado com os exemplos acima que o lado formal da elaboração de obras quaisquer não deve ser compreendido simplesmente como uma "roupagem" externa que acolhe conteúdos sem maiores conseqüências. Nesse sentido, o exame de textos clássicos sob o ponto-devista da noção dos gêneros literários contribui para esclarecer que forma e tema, indissociavelmente ligados no todo compositivo de cada obra, resultam em fatores de igual importância para constituí-las. Dito isso, compreende-se porque as obras dos "agrônomos"" latinos de que nos ocupamos aqui, apesar, como demonstramos, de se vincularem em vários casos ao tratamento dos mesmos tópicos, constituem-se, por sua assimilação a estruturas genéricas distintas, em textos dotados de tantas peculiaridades significativas.

${ }^{18}$ Cf. a opinião de E. Norden (La Prosa ..., p. 177): 'In ciò consiste per noi il pregio precipuo di questo scritto; che contrasto con i libri di Varrone! Anch'egli scrive, a dire il vero, senza eleganza, ma almeno per homines urbani.' 
TITLE. Language and genre in Latin agrarian literature: Cato, Varro and Virgil

ABstRACT. This work proposes a comparative analysis of the linguistic usage associated with two themes related to the agrarian activity in the Virgil's Georgics, De agri cultura of Cato, and De re rustica of Varro from Reate (correct localization of the beehive tree graft). It is expected to demonstrate that the differences related to the linguistic plan, concerning the way these authors treat the themes, are related to the fact that each one of these texts belong to a specific broader typology (respectively, didactic poetry, treaty and dialogue), which means that it is possible to observe here the realization of language in each case (more or less objective, more or less elaborated, more or less skilled...) as a result of the internal constituent determination of each genre.

KEYwords. Latin agrarian literature; genre; language; Cato; Varro; Virgil.

TITRE. Langage et genre dans la littérature agronomique latine: Caton, Varron et Virgile Aвstract. Dans ce travail, nous faisons une analyse comparative de la forme d'élaboration linguistique employée pour deux thèmes liés à l'activité rurale dans les Géorgiques de Virgile, le De agri cultura de Caton et le De re rustica de Varron Réatin (placement convenable du nid d'abeilles et greffe des arbres). On attend montrer que les différences liées au niveau linguistique dans l'abordage de ces thèmes par ces auteurs ont des rapports avec l'appartenance de chaque ouvrage mentionné à un type générique particulier (respectivement, poésie didactique, 'précis' et dialogue), ce qu'implique l'observation de la diverse réalisation du langage comme conséquence des déterminations constitutives internes à chaque genre textuel.

MoTS-CLÉs. Littérature agronomique latine; genres textuels; langage; Caton; Varron; Virgile. 